\title{
Ultrastructure of in-vivo fertilization in superovulated cattle
}

\author{
P. Hyttel, T. Greve* and H. Callesen* \\ Departments of Anatomy and *Animal Reproduction, Royal Veterinary and Agricultural University, \\ Bülowsvej 13, DK-1870 Frederiksberg C, Denmark
}

\begin{abstract}
Summary. Heifers were induced to superovulate by treatment with PMSG or FSH. Subsequently, oestrus was induced with prostaglandins and artificial insemination was performed. Ova were collected from the oviducts and their ultrastructural features were related to an estimated time of ovulation based on the time of the LH peak. With the insemination schedule used, the estimated time of ovulation defined the time at which fertilization was expected to occur.

The ova were characterized as unfertilized, fertilized or possibly fertilized, and a sequence of nuclear and cytoplasmic changes associated with fertilization was revealed. Within $4 \mathrm{~h}$ after the estimated time of ovulation formation of the female and male pronucleus was initiated, and at $5-7 \mathrm{~h}$ swelling of the pronuclei occurred. At $19 \mathrm{~h}$ the pronuclei were closely apposed and synkaryosis was seen, and at $23 \mathrm{~h}$ the first two-cell stage was obtained. Within $2-3 \mathrm{~h}$ after the estimated time of ovulation cortical granule release, development of conspicuous Golgi complexes, and transformation of the smooth endoplasmic reticulum occurred. At $\sim 7 \mathrm{~h}$ parallel arrays of annulate lamellae appeared. In one third of the unfertilized ova deviant oocyte maturation was noticed.
\end{abstract}

Keywords: superovulated cattle; fertilization in vivo; ultrastructure

\section{Introduction}

An increased application of different biotechnologies in cattle reproduction has emphasized the need for methods to control oocyte maturation, fertilization and initial embryonic development in vitro. Further knowledge of the basic mechanisms of these processes under in-vivo as well as in-vitro conditions is therefore needed.

The ultrastructure of maturation of the preovulatory oocyte has been described in detail and related to the time of the preovulatory LH peak, which triggers these processes (unstimulated cattle: Kruip et al., 1983; gonadotrophin-stimulated cattle: Hyttel et al., 1986a). The ultrastructure of oocytes matured in vitro has also been studied (Hyttel et al., 1986b, 1987; Hyttel, 1987). From these studies it is clear that the final maturation of bovine oocytes includes certain well defined nuclear changes and a particular sequence of cytoplasmic events. Ovarian stimulation with exogenous gonadotrophins may lead to deviations in these maturational processes (Hyttel et al., 1986a). However, whether oocytes with deviant maturation can be ovulated and fertilized is not known.

Certain ultrastructural changes associated with in-vivo fertilization in unstimulated cattle have been described by Crozet (1984), as have some comparative ultrastructural aspects of in-vivo and in-vitro fertilization in this species (Brackett et al., 1980). However, none of these investigators has related the structural findings to endocrine characteristics.

The aim of the present study was to relate the ultrastructural changes associated with in-vivo fertilization and initial embryonic development in gonadotrophin-stimulated cattle to the estimated time of ovulation, which defines the expected time of fertilization. 


\section{Materials and Methods}

Animal treatment and collection of ova. Dairy heifers in the mid-luteal phase of the cycle were given a single injection of 1500-3000 i.u. PMSG (Antex: LEO Pharmaceuticals, Ballerup, Denmark) (N=7) or P-FSH (Burns Biotec., Omaha, NE, U.S.A.) $(\mathrm{N}=5)$ twice daily for 5 days in decreasing doses: $5 / 5 \mathrm{mg}, 4 / 4 \mathrm{mg}, 3 / 3 \mathrm{mg}, 2 / 2 \mathrm{mg}$ and $1 / 1 \mathrm{mg}$, respectively. At $39-68 \mathrm{~h}$ after the initial injection the animals were injected with cloprostenol (Estrumat: Lundbeck and Co., Valby, Denmark) to cause luteal regression. Blood samples were obtained every $4 \mathrm{~h}$ after cloprostenol treatment for LH analyses. At 53-59 h after the cloprostenol treatment the animals were artificially inseminated with two straws of frozen semen from a proven fertile bull. At $64-68 \mathrm{~h}$ after the cloprostenol treatment anaesthesia was induced with thiopentone sodium (Leopental: LEO Pharmaceuticals) in a dose of $11 \mathrm{mg} / \mathrm{kg}$ body weight, and maintained with halothane (Fluothane: ICI Pharma, Copenhagen, Denmark) in a closed system. The oviducts were exteriorized through a midline incision and flushed with $2 \times 20 \mathrm{ml}$ modified Dulbecco's PBS (Whittingham, 1971). The isolated ova were randomly assigned to this or other studies.

Hormone analysis. Plasma LH concentration was determined by a rapid and semiquantitative RIA method (R. Høier, personal communication). Briefly, the method is based on the work of Niswender et al. (1969) with the following exceptions. Incubation was performed at room temperature for $3648 \mathrm{~h}$ and immobilized second antibody was used for separation according to the protocol of the manufacturer (UCB-Bioproducts S.A., Braine-l'Alleud, Belgium). The method correlated well $(r=0.99)$ to the Niswender method when samples measured by both methods were compared by linear regression. The intra- and inter-assay coefficients of variation were $2-9 \%$ and $4-15 \%$, respectively, depending on the positions along the dose-response curve. The least detectable amount was $0.5 \mathrm{ng} \mathrm{LH} / \mathrm{ml}$ plasma, derived as twice the standard deviation of the maximum binding.

Tissue preparation. The 51 ova were fixed, block stained, dehydrated and embedded as previously described (Hyttel \& Madsen, 1987). Some of the ova were serially sectioned in semithin and ultrathin section by means of traditional techniques, while most of the ova were sectioned as described by Hyttel \& Madsen (1987). Ultrathin sections were always prepared at the plane where an oocyte nucleus, condensed female chromatin configurations, a polar body, male chromatin configurations, a pronucleus or a nucleus was observed in the semithin sections and/or at the equatorial plane of the ovum. The semithin sections were stained with toluidine blue while the ultrathin sections were contrasted with uranyl acetate and lead citrate and examined in a JEM 1200 EX (Jeol, Tokyo, Japan).

Estimated time of ovulation. The work of Callesen et al. (1986) indicated that mean ovulation time in superovulated cattle was $27 \mathrm{~h}$ after the $\mathrm{LH}$ peak, and this was taken as the estimated time of ovulation in this study. Allowing a maximum of $36 \mathrm{~h}$ after artificial insemination for a capacitated population of spermatozoa to be established in the oviducts (Brackett et al., 1980; Hunter, 1985), the estimated time of ovulation occurred after a capacitated population of spermatozoa was present in the oviducts in all animals. The estimated time of ovulation was therefore considered to define the expected time of fertilization.

\section{Results}

The ova were classified as unfertilized, fertilized or possibly fertilized according to the following definitions. Unfertilized ova were those in which the female chromatin assumed any of the follicular maturational stages previously described (Hyttel et al., 1986a), i.e. up to the metaphase of the second meiotic division, and in which no spermatozoa were found in the ooplasm. Fertilized ova were those in which the female chromatin was activated and in which at least one sperm head or its succeeding stages were found in the ooplasm. Possibly fertilized ova were those in which the female chromatin was activated but in which no sperm head or its succeeding stages were found in the ooplasm.

\section{Unfertilized ova}

General morphology. In general, the metaphase of the second meiotic division was found in a dense area peripherally in the ooplasm of the unfertilized ova (Fig. 1), and their ultrastructure was

Fig. 2. Detail from a fertilized ovum showing the male chromatin at the sperm head stage. The chromatin (C) is still closely associated with the middle piece (MP) of the spermatozoon, and two dense areas (DA) are seen in proximity to the sperm portions. The chromatin is surrounded by vesicles (V) and mitochondria (M) closely associated with the smooth endoplasmic reticulum (SER). $\times 13400$. 


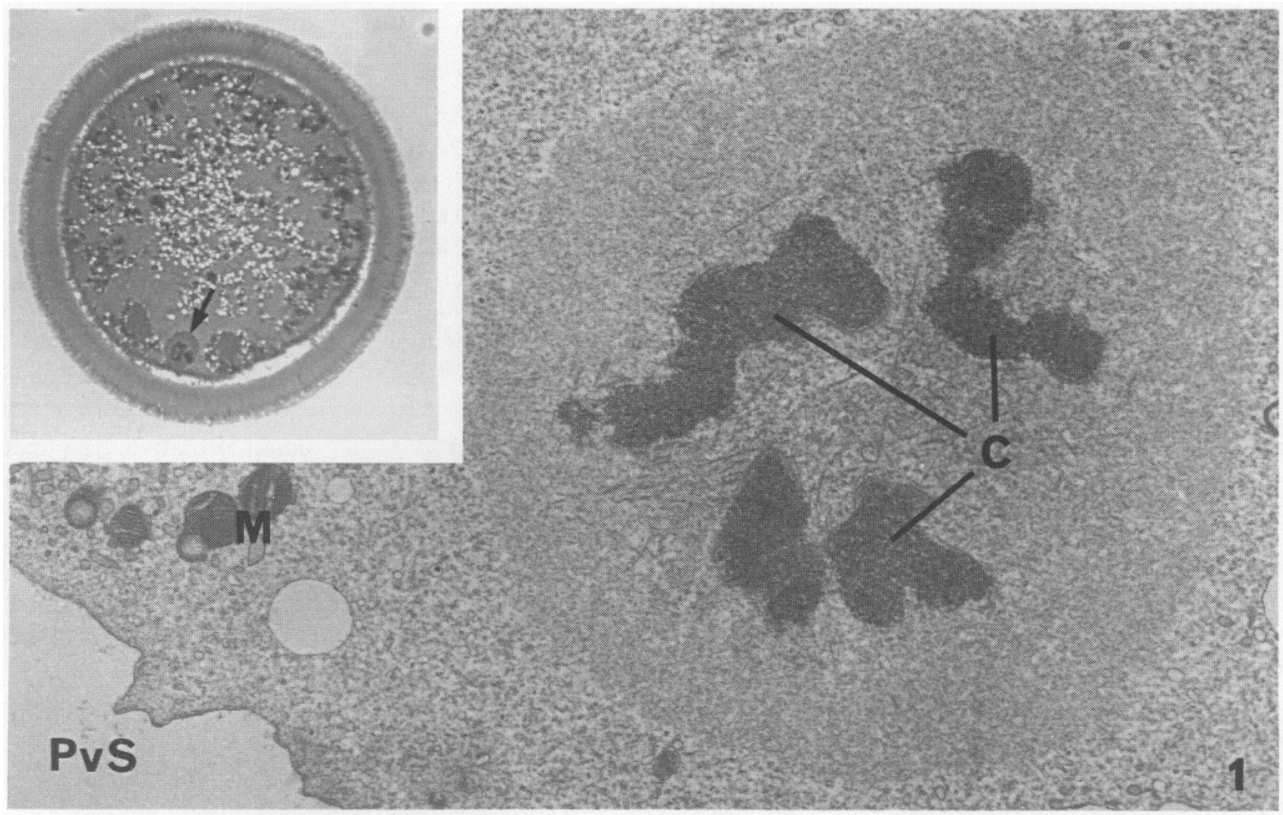

Fig. 1. Detail from an unfertilized ovum showing the perivitelline space (PvS), the metaphase chromosomes $(C)$ located in a dense area of the ooplasm, and mitochondria $(\mathrm{M})$. Note the microtubules between the chromosomes. $\times 7800$. Inset: Unfertilized ovum indicating the peripheral location of the chromosomes in the dense area (arrow). $\times 300$.

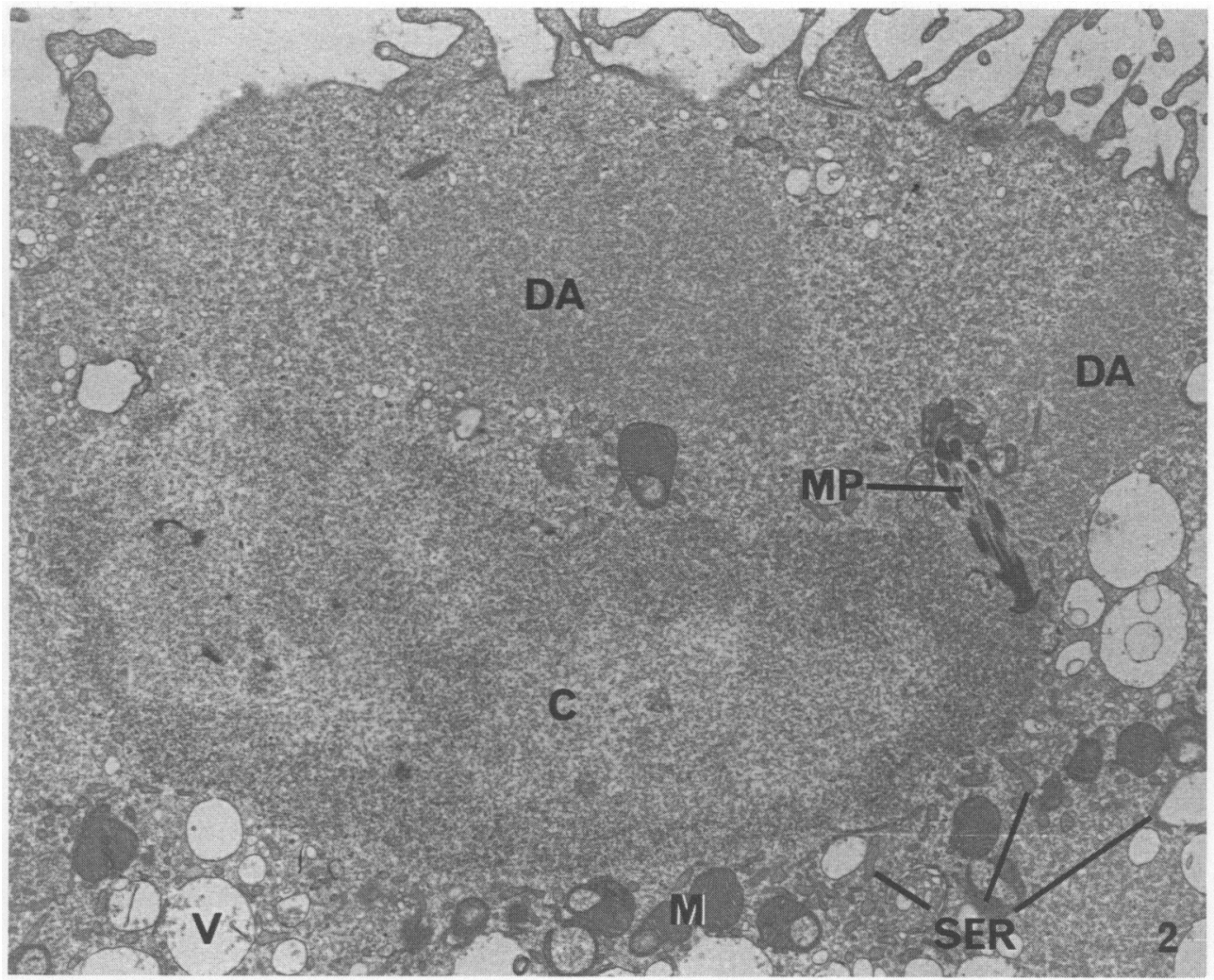


similar to that described for mature bovine oocytes immediately before ovulation (Hyttel et al., 1986a). Characteristically, the zona pellucida had spermatozoa neither attached to nor embedded in it. The first polar body was degenerating in most ova, and by $>7 \mathrm{~h}$ after the estimated time of ovulation it was generally not observed. A certain degree of clustering of the cortical granules was noticed with increasing time to the estimated time of ovulation.

Deviant oocyte maturation. Two unfertilized ova collected at $4 \mathrm{~h}$ and one ovum collected at $15 \mathrm{~h}$ after the estimated time of ovulation displayed a peripheral ooplasmic location of the mitochondria. This phenomenon was interpreted as a sign of cytoplasmic immaturity because mature bovine oocytes are characterized by evenly distributed mitochondria (Hyttel et al., 1986a, b).

One unfertilized ovum collected at $15 \mathrm{~h}$ after the estimated time of ovulation showed retardation in both nuclear and cytoplasmic maturation. The oocyte nucleus was at the breakdown stage (Hyttel et al., 1987), the mitochondria were located peripherally, the cortical granules were organized in big clusters, and the Golgi complexes were well developed as expected for oocytes at this immature stage (Hyttel et al., 1986a).

\section{Fertilized ova}

The fertilized ova comprised one-celled ova, i.e. zygotes, and a two-cell stage. All fertilized ova had a few acrosome-reacted spermatozoa attached to and/or embedded in the zona pellucida, in which more or less tangentially orientated sperm tracks were always observed.

Zygotes. After fusion of the two gametes a number of nuclear and cytoplasmic changes was observed in the ovum. The earliest observed stage of male chromatin development was the decondensing sperm head (not membrane bound) located peripherally in the ooplasm (sperm head stage, Fig. 2). Subsequently, the chromatin was gradually invested by a nuclear envelope developed from cisternae of the smooth endoplasmic reticulum (SER), which appeared to migrate towards it (pronucleus I stage, Figs 3 \& 4). Upon compietion of formation of the nuclear envelope a sperm head-shaped pronucleus appeared (pronucleus II stage, Fig. 5), and swelling and enlargement resulted in formation of a spherical pronucleus (pronucleus III stage, Fig. 6). At the pronucleus I

Fig. 3. Detail from a fertilized ovum showing the male chromatin at the pronucleus I stage. The chromatin (C) is still sperm head shaped and closely associated with the middle piece (MP) of the spermatozoon. Mitochondria (M) associated with smooth endoplasmic reticulum (SER) are seen in the proximity of the male chromatin. Note the dense areas (DA) associated with the middle piece of the spermatozoon, which is orientated parallel to the oocyte surface facing the zona pellucida $(\mathrm{ZP}) . \times 4100$.

Fig. 4. The boxed area from Fig. 3 showing the migration of cisternae of the smooth endoplasmic reticulum (SER) towards the male chromatin (C) where they form fragments of nuclear envelope (NE). The smooth endoplasmic reticulum is also closely associated with the mitochondria (M). $\times 14000$.

Fig. 5. Detail from a fertilized ovum showing the male chromatin at the pronucleus II stage. The chromatin $(C)$ is still sperm head shaped and surrounded by a complete nuclear envelope. The pronucleus is still associated with the middle piece (MP) of the spermatozoon, and a dense area (DA), mitochondria (M), smooth endoplasmic reticulum (SER), and a Golgi complex (G) is also seen. $\times 10800$. Inset: Survey picture from the same ovum showing the peripherally located pronucleus (arrow) and the middle piece of the spermatozoon (arrowhead) orientated parallel to the oocyte surface. Note the two clusters of cumulus cells, which are attached to the zona pellucida. $\times 300$. 

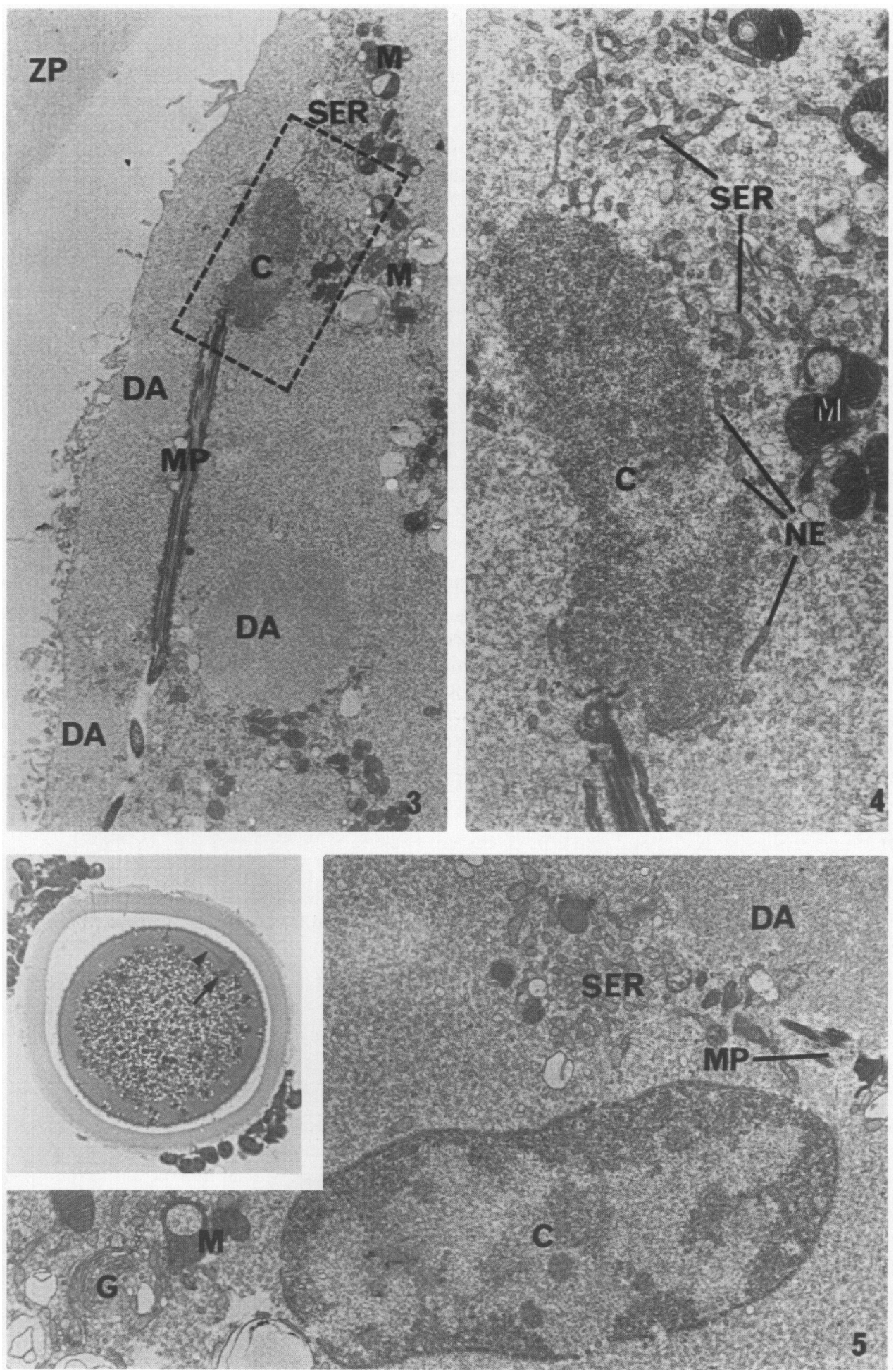

c

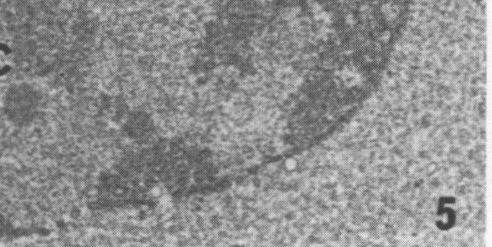




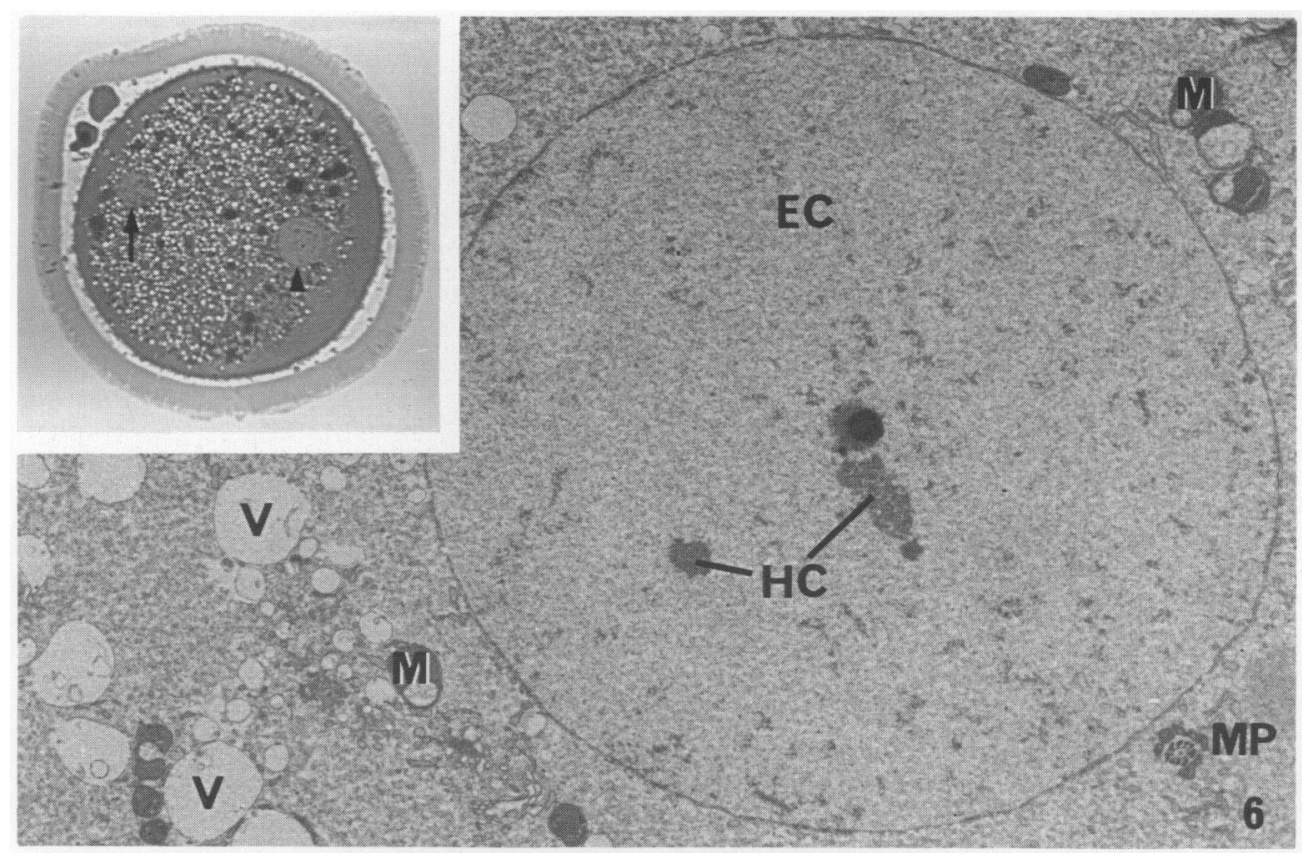

Fig. 6. Detail from a fertilized ovum showing the male chromatin at the pronucleus III stage characterized by the spherical appearance of the pronucleus, which contains large euchromatic (EC) and sparse heterochromatic formations (HC). The pronucleus is still associated with the middle piece (MP) of the spermatozoon, and it is surrounded by vesicles (V) and mitochondria (M) $\times 5900$. Inset: Fertilized ovum showing the female (arrow) as well as the male chromatin (arrowhead) at the pronucleus III stage. The female pronucleus is located in the proximity of the second polar body, which is seen in two sections in the perivitelline space, while the male pronucleus was identified by its association with the middle piece of the spermatozoon $\times 300$.

and II stages only sparse decondensation of the chromatin occurred, and the middle piece of the spermatozoon was still closely associated with the developing pronucleus. At the pronucleus III stage large euchromatic and sparse heterochromatic areas were seen. Occasionally, the middle piece could still be observed associated with the pronucleus, and on some occasions intranuclear annulate lamellae were noted.

Upon gamete fusion the dense area containing the metaphase of the second meiotic division fragmented and disappeared, and ooplasm of normal density contained the chromosomes (condensed chromatin stage) at the anaphase configuration (Fig. 7). Subsequently, the portion of the chromosomes that remained in the ovum was gradually invested by a nuclear envelope developed from the SER (pronucleus I stage, Fig. 8). Upon completion of formation of the nuclear envelope an irregularly shaped pronucleus appeared (pronucleus II stage, Fig. 9), and swelling and enlargement resulted in formation of a spherical pronucleus (pronucleus III stage, Fig. 6).

From the pronucleus I stage a gradual chromatin decondensation was seen, and the pronucleus III stage had large euchromatic and sparse heterochromatic areas. The abstriction of the second

Fig. 9. Detail from a fertilized ovum showing the female chromatin at the pronucleus II stage. The chromatin $(\mathrm{C})$ is surrounded by a complete nuclear envelope. Microtubules (arrows) project towards the midbody (MB) and further into the second polar body (PB2), which is in the process of being abstricted. The pronucleus is associated with vesicles (V), mitochondria (M), and a Golgi complex $(\mathrm{G}) . \times 7400$. 

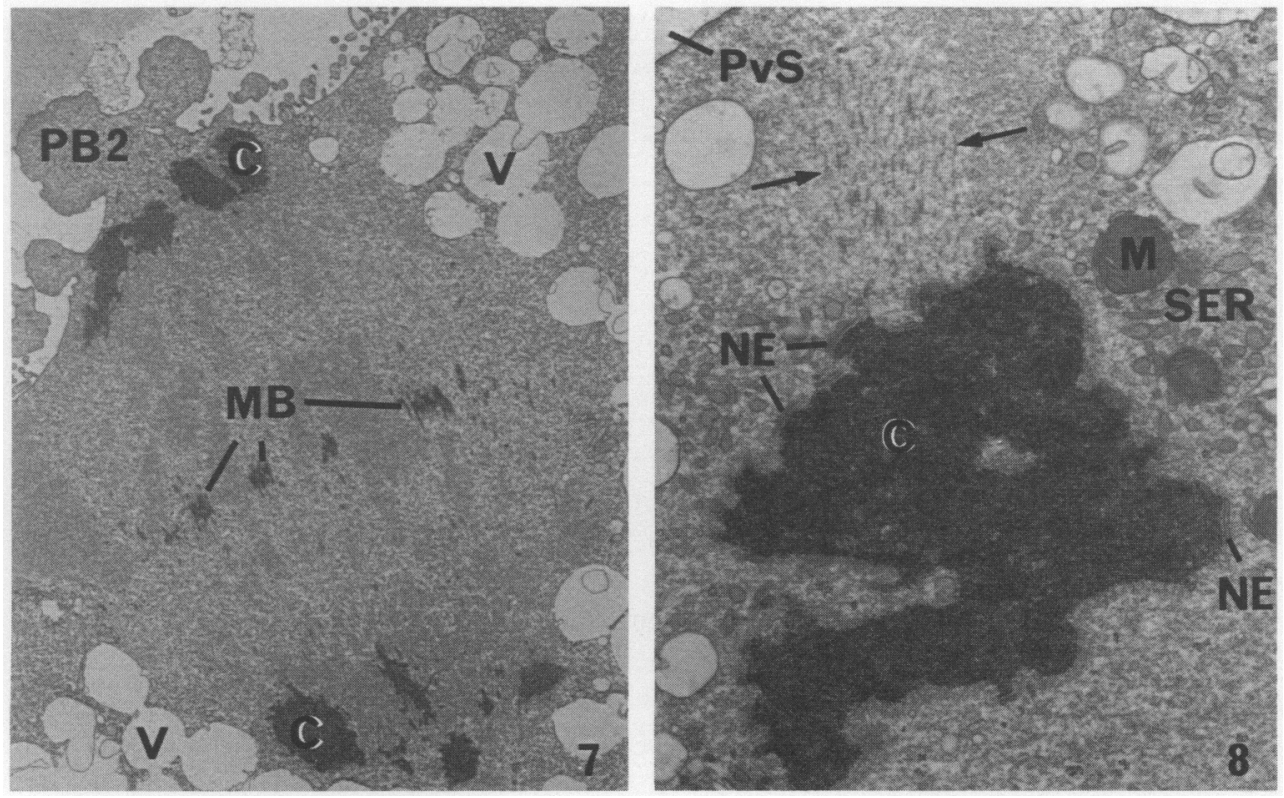

Fig. 7. Detail from a fertilized ovum showing the female chromosomes (C) at the anaphase with the midbody (MB) being formed. The abstriction of the second polar body (PB2) is initiated. Note how the dense area, which contains the metaphase chromosomes in the unfertilized ova, is fragmented and dissolved. The anaphase is surrounded by numerous vesicles (V). $\times 3800$.

Fig. 8. Detail from a fertilized ovum showing the female chromosomes at the pronucleus I stage. The chromosomes (C) are associated with fragments of nuclear envelope (NE) developed from the smooth endoplasmic reticulum (SER), which is also closely associated with the mitochondria (M). Note the microtubules (arrows) which are projecting from the chromosomes. $\times 12500$.

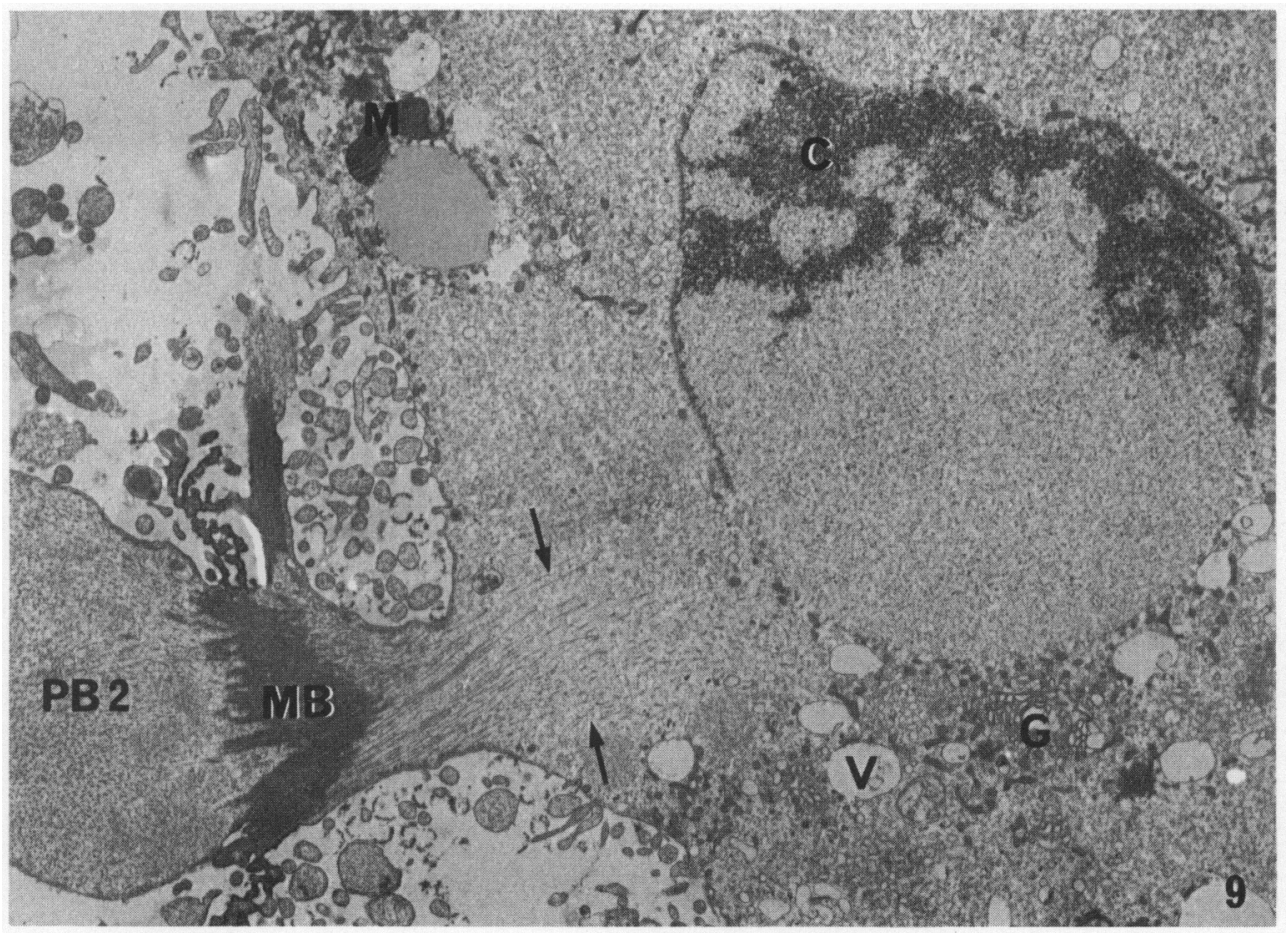


polar body was initiated at the condensed chromatin stage (Fig. 7), and at the pronucleus II stage it was either completed or the polar body was still connected to the ovum by a cytoplasmic bridge containing microtubules and the midbody (Fig. 9). The second polar body contained condensed chromatin configurations, mitochondria, vesicles, and one or more areas of ooplasm with increased density.

After the female and the male pronucleus III stage the two pronuclei became closely apposed (pronucleus IV stage, Fig. 10), and chromatin condensation was observed, especially in the regions facing the opposite pronucleus. Also, the nuclear envelopes became undulating in this area, and at the late pronucleus IV stage the envelopes dissolved into irregular vesicles and tubules. Upon dismantling of the nuclear envelopes the condensed parental chromosomes became arranged centrally in the ooplasm in a dense area devoid of most other organelles (synkaryosis stage, Fig. 11). The dense area was surrounded by conspicuous Golgi complexes, and cisternae of the SER extended into it. Subsequently, the nuclei of the two-cell stage were formed in each pole of the zygote, and different stages of cytokinesis were seen (binucleus stage, Fig. 12). Again, intranuclear annulate lamellae were encountered.

Within the first $2-3 \mathrm{~h}$ after the estimated time of ovulation the release of the cortical granules from the ooplasm was more or less completed, and their spherical electron-dense content was dispersed in the perivitelline space (Fig. 13). This reaction had taken place in all fertilized and possibly fertilized ova. During the same period of time the clustering of the SER decreased and the size of the Golgi complexes increased. In Heifer 10 (Table 1), in which the nuclear changes were retarded, a delay in the transformation of SER and Golgi complexes was also observed. The Golgi

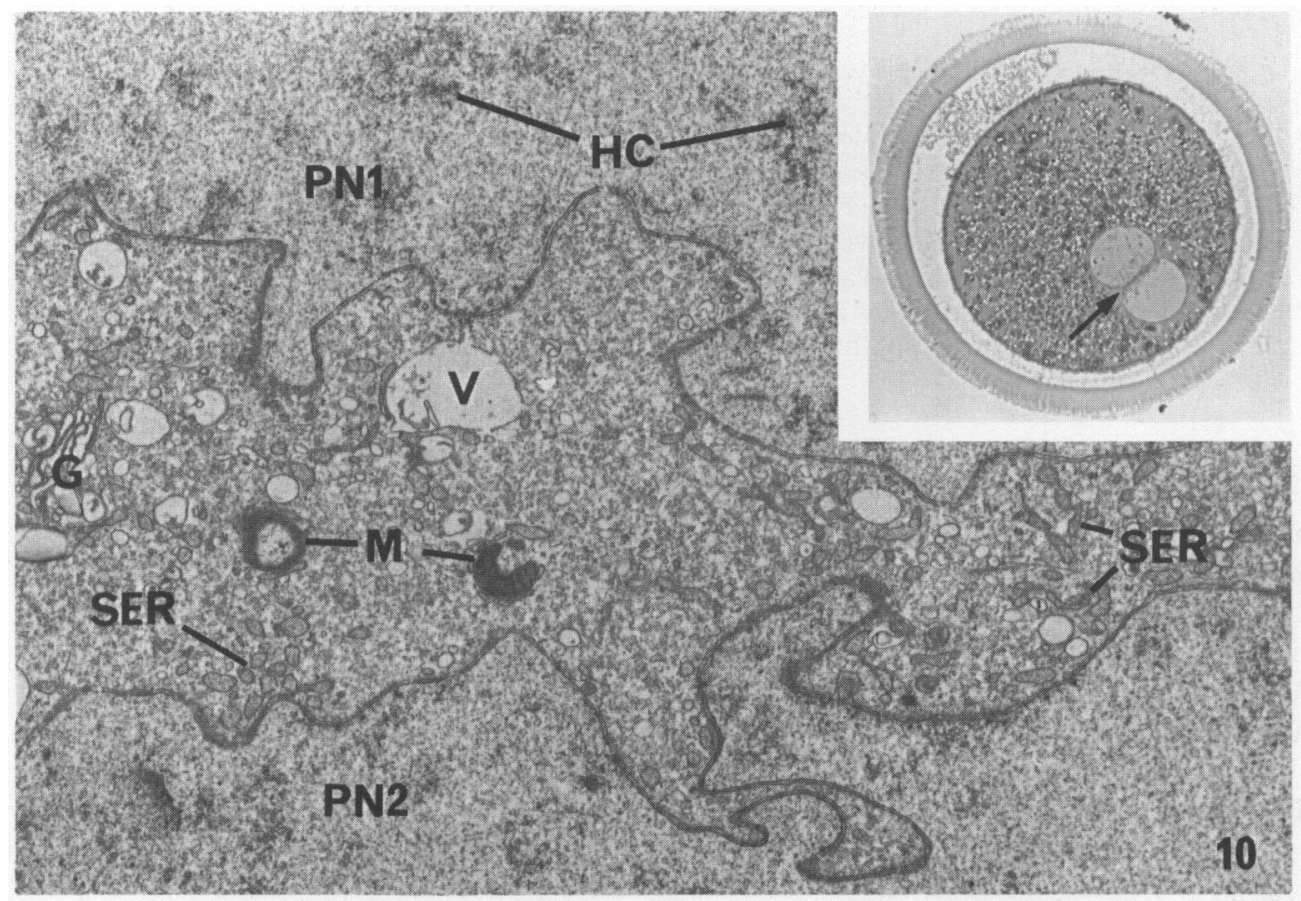

Fig. 10. Detail from a fertilized ovum at the pronucleus IV stage. The two pronuclei (PN1/PN2) are separated by a narrow cytoplasmic bridge containing vesicles (V), mitochondria (M), a Golgi complex (G) and smooth endoplasmic reticulum (SER). Note the undulation of the nuclear envelopes and the frequent occurrence of heterochromatic formations $(\mathrm{HC}) \times 10000$. Inset: Fertilized ovum at the pronucleus IV stage indicating the intimate relationship between the two pronuclei (arrow). $\times 300$. 


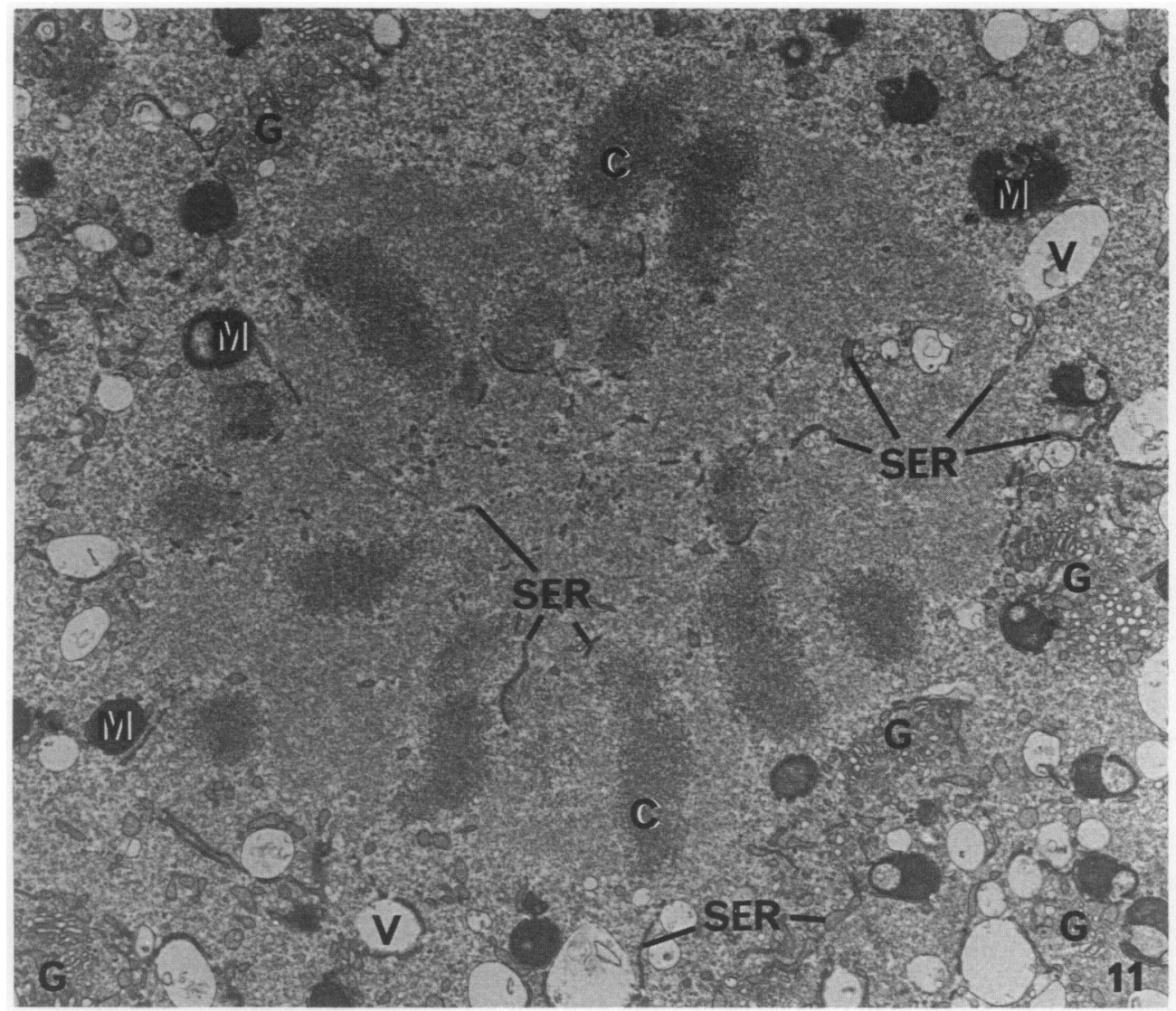

Fig. 11. Detail from a fertilized ovum at the synkaryosis stage. The parental chromosomes (C) are located in a dense area of the ooplasm, which is surrounded by conspicuous Golgi complexes $(G)$, vesicles (V), and mitochondria (M). Cisternae of smooth endoplasmic reticulum (SER) are closely associated with the vesicles and the mitochondria, and invade the chromosome containing area. $\times 7800$.

complexes were especially conspicuous around the pronuclei. At about $7 \mathrm{~h}$ after the estimated time of ovulation, i.e. at the peak of appearance of pronucleus III stages (Table 1), numerous parallel arrays of annulate lamellae developed from certain portions of the SER (Fig. 14), and a narrow lining of SER cisternae was formed along the oolemma.

During abstriction of the second polar body the mitochondria migrated towards the site of polar body formation. A degenerated first polar body was often found in the perivitelline space until $\sim 7 \mathrm{~h}$ after the estimated time of ovulation but it was generally absent at the later stages.

During cytokinesis a symmetrical cleavage furrow was formed towards which mitochondria and vesicles migrated. Later, two cellular compartments, which were only connected by a narrow cytoplasmic bridge containing microtubules and the midbody, were formed. A marked Golgi complex activity was found at the origins of this cytoplasmic bridge (Fig. 12).

The two-cell stage. The first polar body was absent but a degenerated second polar body was found in the perivitelline space. The mitochondria and vesicles were located centrally in the cells, i.e. blastomeres, around the nuclei, leaving a relatively organelle-free zone peripherally. The morphology of the organelles resembled that described for the zygotes. 


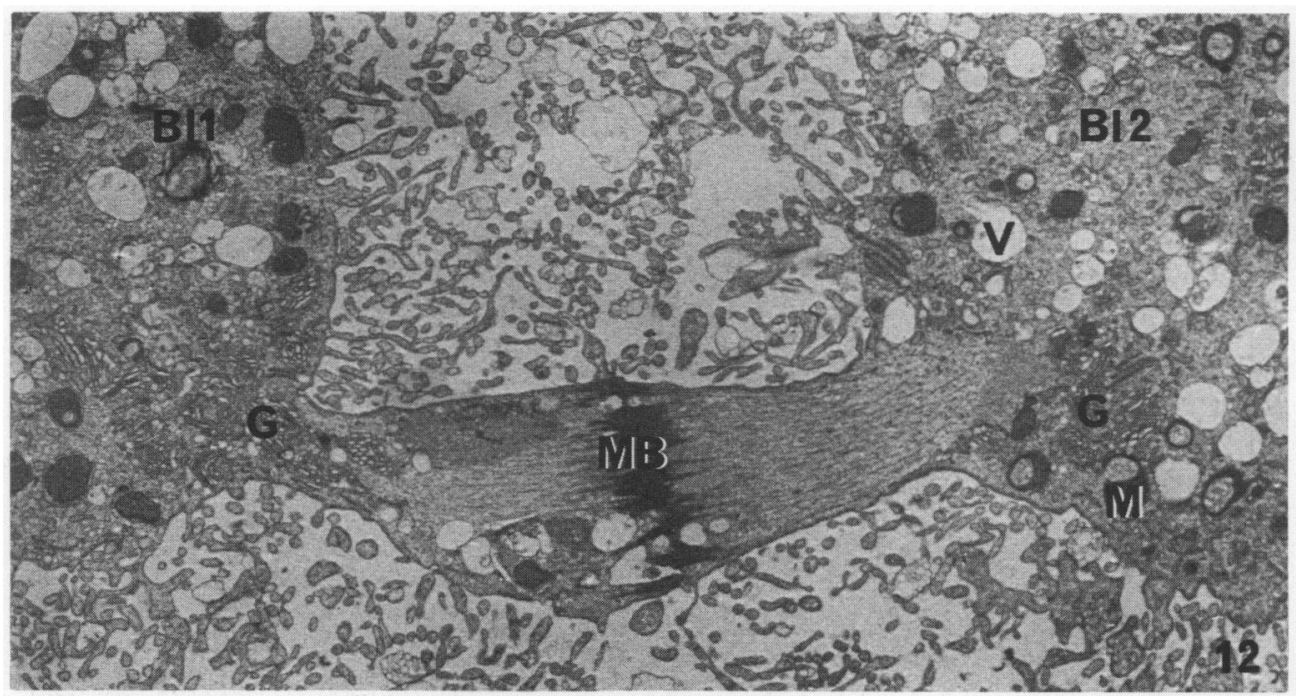

Fig. 12. Detail from a fertilized ovum at the binucleus stage showing the developing two blastomeres (B1 1/B12), which are connected by a cytoplasmic bridge containing the midbody (MB). In the blastomeres, vesicles $(\mathrm{V})$ and mitochondria $(\mathrm{M})$ are seen, and at the origins of the cytoplasmic bridge conspicuous Golgi complexes $(G)$ are present. $\times 5800$.

\section{The chronology of fertilization}

The nuclear developmental stages of the ova were closely related to the estimated time of ovulation as indicated in Table 1 . Within the first $4 \mathrm{~h}$ the predominant stages were condensed chromatin, sperm head and pronucleus I. At 5-7 h the proportion of pronucleus II and pronucleus III stages increased,

Table 1. The structural classification of tubal ova relative to the estimated time of ovulation (EO) in superovulated heifers

\begin{tabular}{cccl}
\hline Heifer & $\begin{array}{c}\text { Time }(\mathrm{h}) \\
\text { after EO }\end{array}$ & $\begin{array}{c}\text { Unfertilized } \\
\text { ova (no.) }\end{array}$ & \multicolumn{1}{c}{$\begin{array}{c}\text { Possibly fertilized and } \\
\text { fertilized ova (female/male) }\end{array}$} \\
\hline 1 & 2 & & PNI/NO \\
2 & 3 & & PNI/SH, PNI/PNI, PNI/PNII \\
3 & 3 & 3 & CC/NO*, PNI/NO+, PNI/PNI \\
4 & 4 & 3 & CC/NO, PNI/SH, PNI/NO, PNI/PNI \\
5 & 5 & 1 & PNI/PNI, NO/PNI, PNII/PNII, PNIII/ \\
7 & 7 & & PNII \\
8 & 7 & 3 & PNII/PNII, NO/PNI PNIII/PNIII, PNIII/PNIII, \\
9 & 10 & 2 & PNIII/PNIII, PNIII/PNIII, PSp \\
10 & 15 & & CC/NO, PNI/NO \\
11 & 19 & & PNIV, PNIV, PNIV, PNIV, PNIV, PNIV, \\
12 & 23 & & PNIV $\$$ SK \\
& & & PNIV, PNIV, BN, BN, 2-cell stage \\
\hline
\end{tabular}

$\mathrm{NO}=$ not observed; $\mathrm{CC}=$ condensed chromatin stage; $\mathrm{SH}=$ sperm head stage; $\mathrm{PNI}=$ pronucleus $\mathrm{I}$ stage; $\mathrm{PNII}=$ pronucleus II stage; $\mathrm{PNIII}=$ pronucleus III stage: $\mathrm{PNIV}=$ pronucleus IV stage; $\mathrm{SK}=$ synkaryosis stage; $\mathrm{BN}=$ binucleus stage; $\mathrm{PSp}=$ polyspermy and fragmentation.

*Sperm middle piece in perivitelline space.

†Sperm tail entering ooplasm.

$\ddagger$ Degenerated ovum. 
and at $19 \mathrm{~h}$ the pronucleus IV stage was dominating, but also a synkaryosis stage was encountered. At $23 \mathrm{~h}$ the binucleus stage had developed and the first two-cell stage emerged.

The velocity with which the nuclear changes occurred varied between as well as within animals. Heifer 10 especially displayed retarded ovum development. Also within the individual ova minor variations in the speed by which the female and the male pronucleus formation progressed was noticed. For example, in Heifers 2 and 4 formation of the nuclear envelope of the female pronucleus was initiated earlier than that of its male counterpart, which, in turn, was sometimes more advanced with respect to the completion of envelope formation and swelling (Heifers 2 and 7 ).

\section{Deviant fertilization}

One ovum collected $7 \mathrm{~h}$ after the estimated time of ovulation was fragmented into two symmetrical portions of which one contained a male pronucleus III stage while the other displayed both a female and a male pronucleus III stage. This ovum lacked half of the zona pellucida, and in the remaining perivitelline space a degenerated first and a second polar body were found. Cortical
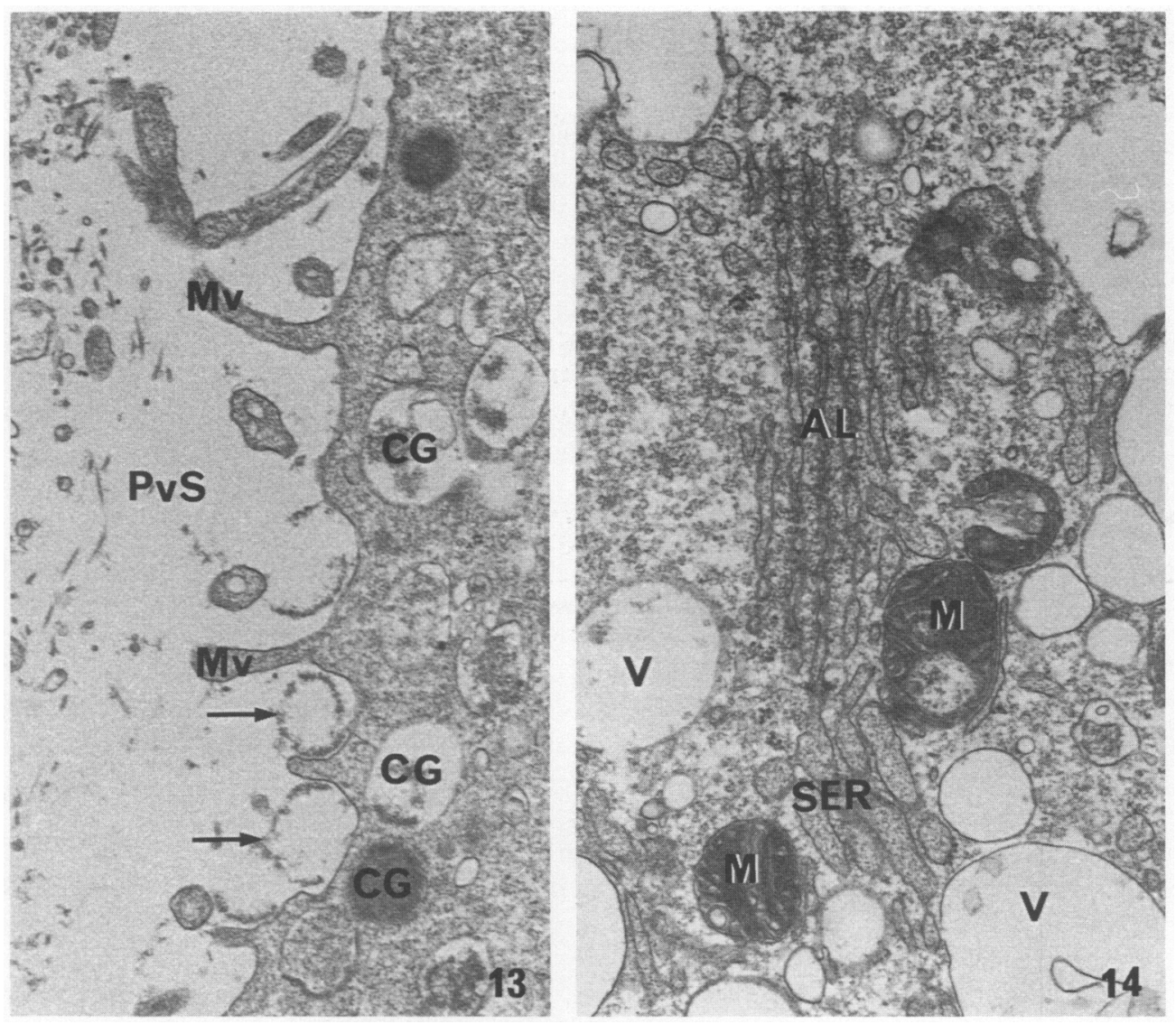

Fig. 13. Detail from a fertilized ovum showing release of the content of cortical granules into the perivitelline space. In the ooplasm cortical granules (CG) are seen, and between the bases of the microvilli $(\mathrm{Mv})$ the released spherical content of the granules (arrows) is present. $\times 22400$.

Fig. 14. Detail from a fertilized ovum showing the development of parallel arrays of annulate lamellac (AL) from the smooth endoplasmic reticulum (SER). Note the close association between the SER, vesicles (V) and mitochondria (M). $\times 25800$. 
granule release had taken place in this ovum. Another ovum at the pronucleus IV stage collected $20 \mathrm{~h}$ after the estimated time of ovulation showed karyolysis and multiple ruptures of the oolemma.

\section{Possibly fertilized ova}

The morphology of these ova resembled that of fertilized ova at identical stages of female nuclear development. In one ovum the middle piece of a spermatozoon was found in the perivitelline space while a sperm tail entering the ooplasm was found in another (Heifer 3).

\section{Cumulus cell morphology}

Up to $11 \mathrm{~h}$ after the estimated time of ovulation one third of the unfertilized ova were associated with cumulus cells, and in more than half of the fertilized and possibly fertilized ova cumulus cells were found up to $5 \mathrm{~h}$. After these times all ova were devoid of cumulus cells. The cumulus cells were arranged in compact clusters leaving the major part of the zona pellucida free. The cells were very rich in rough endoplasmic reticulum, Golgi complexes and secondary lysosomes. Multivesicular bodies were occasionally found.

\section{Discussion}

The present study is the first attempt to describe the ultrastructure of fertilization in cattle relative to an ovulation time estimated from the preovulatory LH peak. The general ultrastructural features associated with fertilization are well known from several studies of man (Soupart \& Strong, 1974; Trounson \& Sathananthan, 1984; Pereda \& Coppo, 1985; Sathananthan \& Trounson, 1985), pig (Szöllösi \& Hunter, 1973), and rodents (Zamboni \& Mastroianni, 1966; Longo \& Anderson, 1969; Zamboni et al., 1972; Thompson et al., 1974; Oh \& Brackett, 1975). Previous ultrastructural studies of cattle have also given some information on the process of fertilization, although in a more fragmentary form (Brackett et al., 1980; Crozet, 1984).

The possibly fertilized ova in this study were probably fertilized, but the sperm heads could not be traced in spite of a very delicate sectioning technique. However, if these ova had been parthenogenetically activated later developrinental stages of the female chromatin would have been expected and there would probably have been failure of cortical granule release (Brackett et al., 1980).

The time required for pronuclear apposition in cattle seems to be longer than that reported for the pig (Hunter, 1972). After apposition chromatin condensation, as described for the pig (Hunter, 1972) and the mouse (Zamboni et al., 1972), and dismantling of the nuclear envelopes occurred. The mechanism of dismantling appeared to be similar to that reported for oocyte nucleus breakdown in cattle when the nuclear envelope is dissolved into irregular vesicles and tubules, which are probably included in the SER (Hyttel et al., 1987). The fact that the prophase of the first mitotic division, as indicated by chromatin condensation in the pronuclei, was initiated before and during the dissolution of the nuclear envelopes suggests that the parental chromosomes are not mixed during synkaryosis in accordance with reports for rodents (Longo \& Anderson, 1969; Zamboni et al., 1972; Thompson et al., 1974).

After fertilization annulate lamellae apparently develop from certain portions of the SER as reported for human zygotes (Sathananthan \& Trounson, 1985). The present study revealed that annulate lamellae develop concomitant with the swelling of the pronuclei. In human ova the annulate lamellae are predominantly found in proximity to the pronuclei (Soupart \& Strong, 1974) and they are more frequent in ova with polyspermic pronucleus development (Sathananthan \& Trounson, 1985). In rabbit ova they are not seen until the fully developed pronuclei migrate centrally in the ovum (Zamboni \& Mastroianni, 1966). Altogether these findings indicate a relationship between nuclear envelope formation and the development of annulate lamellae, and 
suggest that the lamellae may represent a certain overproduction of nuclear envelope fragments with which they share structural similarities (Soupart \& Strong, 1974; Thompson et al., 1974). This hypothesis is supported by the finding of intranuclear annulate lamellae in accordance with reports for human (Soupart \& Strong, 1974; Trounson \& Sathananthan, 1984; Pereda \& Coppo, 1985), cattle (Crozet, 1984) and pig (Szöllösi \& Hunter, 1973) ova.

In one third of the unfertilized ova certain structural deviations of the nuclear and/or cytoplasmic oocyte maturation were noticed. In superovulated cattle nuclear and cytoplasmic deviations are encountered during preovulatory oocyte maturation (Hyttel et al., 1986a). Taken together these findings suggest that treatment of cattle with exogenous gonadotrophins is associated with certain deviations in the process of oocyte maturation and may lead to ovulation of immature oocytes that probably have a reduced ability to undergo normal fertilization. This notion is substantiated by invitro fertilization experiments, which show that immature oocytes cannot be fertilized (K. P. Xu, personal communication).

We thank Miss Inger Madsen for skilful technical assistance. The work was supported by grant numbers 13-3795 and 5.10.17.06 from the Danish Agricultural and Veterinary Research Council and Leo Research Foundation.

\section{References}

Brackett, B.G., Oh, Y.K., Evans, J.F. \& Donawick, W.J. (1980) Fertilization and early development of cow ova. Biol. Reprod. 23, 189-205.

Callesen, H., Greve, T. \& Hyttel, P. (1986) Preovulatory endocrinology and oocyte maturation in superovulated cattle. Theriogenology 25, 71-86.

Crozet, N. (1984) Ultrastructural aspects of in vivo fertilization in the cow. Gamete Res. 10, 241-251.

Hunter, R.H.F. (1972) Fertilization in the pig: sequence of nuclear and cytoplasmic events. J. Reprod. Fert. 29, 395-406.

Hunter, R.H.F. (1985) Experimental studies of sperm transport in sheep, cows and pigs. Vet. Rec. 116, 188.

Hyttel, P. (1987) Bovine cumulus-oocyte disconnection in vitro. Anat. Embryol. 176, 41-44.

Hyttel, P. \& Madsen, I. (1987) Rapid method to prepare mammalian oocytes and embryos for transmission electron microscopy. Acta anat. 129, 12-14.

Hyttel, P., Callesen, H. \& Greve, T. (1986a) Ultrastructural features of preovulatory oocyte maturation in superovulated cattle. J. Reprod. Fert. 76, 645-656.

Hyttel, P., Xu, K.P., Smith, S. \& Greve, T. (1986b) Ultrastructure of in-vitro oocyte maturation in cattle. J. Reprod. Fert. 78, 615-625.

Hyttel, P., Xu, K.P., Smith, S., Callesen, H. \& Greve, T. (1987) Ultrastructure of the final nuclear maturation of bovine oocytes in vitro. Anat. Embryol. 176, 35-40.

Kruip, T.A.M., Cran, D.G., van Beneden, T.H. \& Dieleman, S.J. (1983) Structural changes in bovine oocytes during final maturation in vivo. Gamete Res. 8, 29-47.

Longo, F.J. \& Anderson, E. (1969) Cytological events leading to the formation of the two-cell stage in the rabbit: association of the maternally and paternally derived genomes. J. Ultrastruct. Res. 29, 86-118.

Niswender, G.D., Reichert, L.E., Jr, Midgley, A.R. \& Nalbandov, A.V. (1969) Radioimmunoassay for bovine and ovine luteinizing hormone. Endocrinology 84, $1166-1173$.
Oh, Y.K. \& Brackett, B.G. (1975) Ultrastructure of rabbit ova recovered from ovarian follicles and inseminated in vitro. Fert. Steril. 26, 665-685.

Pereda, J. \& Coppo, M. (1985) Ultrastructure of a twocell human embryo fertilized in vivo. Ann. N.Y. Acad. Sci. 442, 416-419.

Sathananthan, A.H. \& Trounson, A.O. (1985) The human pronuclear ovum: fine structure of monospermic and polyspermic fertilization in vitro. Gamete Res. 12, 385-398.

Soupart, P. \& Strong, P.A. (1974) Ultrastructural observations on human oocytes fertilized in vitro. Fert. Steril. 25, 11-44.

Szöllösi, D. \& Hunter, R.H.F. (1973) Ultrastructural aspects of fertilization in the domestic pig: sperm penetration and pronucleus formation. J. Anat. 116, 181-206.

Thompson, R.S., Smith, D.M. \& Zamboni, L. (1974) Fertilization of mouse ova in vitro: an electron microscopic study. Fert. Steril. 25, 22-249.

Trounson, A. \& Sathananthan, A.H. (1984) The application of electron microscopy in the evaluation of two- to four-cell human embryos cultured in vitro for embryo transfer. J. In Vitro Fert./Embryo Transfer 1, 153-165.

Whittingham, D.G. (1971) Survival of mouse embryos after freezing and thawing. Nature, Lond. 233, 125-126.

Zamboni, L. \& Mastroianni, L., Jr (1966) Electron microscopic studies on rabbit ova II. The penetrated tubal ovum. J. Ultrastruct. Res. 14, 118-132.

Zamboni, L., Chakraborty, J. \& Smith, D. (1972) First cleavage division of the mouse zygote. An ultrastructural study. Biol. Reprod. 7, 170-193. 